\title{
Knowledge, Attitudes and Practices of Mothers Regarding Exclusive Breastfeeding in Rural Areas of Brobo (Côte d'Ivoire)
}

\author{
Aka-Tanoh Koko Aude-Hélène*, Avi-Siallou Christelle Honorine, Yeboua Kossonou Roland, \\ Yao Kouassi Christian, Akandji Iburaima, Adou Leioh Roméo, Sahi Gnantin Landryse, \\ Amani Ehi Alexise, Asse Kouadio Vincent \\ Department of the University Hospital of Bouaké, Bouaké, Côte d'Ivoire \\ Email: ^audeaka@gmail.com, avichristelle611@gmail.com, rolandyeboua13@gmail.com, yaokc777@gmail.com, \\ iburaima@yahoo.com, leioh91@hotmail.fr, firstsahi@yahoo.com, amanialexise91@gmail.com, assevinc2014@gmail.com
}

How to cite this paper: Aude-Hélène, A.-T.K., Honorine, A.-S.C., Roland, Y.K., Christian, Y.K., Iburaima, A., Roméo, A.L., Landryse, S.G., Alexise, A.E. and Vincent, A.K. (2021) Knowledge, Attitudes and Practices of Mothers Regarding Exclusive Breastfeeding in Rural Areas of Brobo (Côte d'Ivoire). Open Journal of Pediatrics, 11, 694-705.

https://doi.org/10.4236/ojped.2021.114065

Received: October 20, 2021

Accepted: December 5, 2021

Published: December 8, 2021

Copyright ( 2021 by author(s) and Scientific Research Publishing Inc. This work is licensed under the Creative Commons Attribution International License (CC BY 4.0).

http://creativecommons.org/licenses/by/4.0/ (c) (i) Open Access

\begin{abstract}
Introduction: In Côte d'Ivoire, despite awareness raising among mothers by health authorities and health care providers, the exclusive breastfeeding rate is still low, $23 \%$. This rate seems even lower in rural areas. The objective of the study was to evaluate the knowledge, attitudes and practices of mothers regarding exclusive breastfeeding for the reduction of malnutrition in rural areas. Methods: This was a descriptive and analytical cross-sectional study conducted in Brobo from July to September 2020. It included consenting mothers of infants aged 0 to 24 months. Mothers' knowledge, attitudes and practice were assessed by an anonymous structured questionnaire with a performance threshold set at $75 \%$. Factors associated with exclusive breastfeeding were investigated by the Chi-square test at the $5 \%$ level of significance. Results: The average age of the 183 mothers was 25 years (extremes 13 and 49 years). They were primigravida (33\%) and had a low socioeconomic level (84\%). The mothers knew the definition of exclusive breastfeeding (33\%). They knew that breastfeeding promoted ideal infant growth (64\%) and protected against diarrhea and infection (18\%). They also knew that breastfeeding reduced the mother's risk of cancer (16\%) and strengthened the mother-infant bond (7\%). The mothers interviewed stated that they had put the baby to the breast within the first hour after delivery in $2 \%$ and $63 \%$ of them gave the baby colostrum. Mothers were confident about breastfeeding (91\%) and exclusive breastfeeding until 6 months of age represented $9 \%$. The factor associated with lack of knowledge of exclusive breastfeeding was not attending school (OR 0.26 ; 95\%CI $0.14-0.48 ; \mathrm{p}<0.01)$ and those associated with good practice of exclusive breastfeeding were not attending school (OR 4.94;
\end{abstract}


95\%CI $1.09-22.21 ; \mathrm{p}=0.03$ ) and multiparity (OR 0.30; 95\%CI $0.09-0.97 ; \mathrm{p}$ $=0.04)$. Conclusion: The mothers interviewed in the rural areas of Brobo have insufficient knowledge, attitudes and practices regarding exclusive breastfeeding. To improve this situation, we recommend capacity building of mothers through awareness raising.

\section{Keywords}

Exclusive Breastfeeding, Rural Environment, Infant, Brobo

\section{Introduction}

In 2018 worldwide, 2.7 million children had died from malnutrition. This accounted for $45 \%$ of global deaths [1]. The majority of these deaths were in Africa and Asia. Regarding sub-Saharan Africa, despite the promotion of exclusive breastfeeding in most countries, many children still do not benefit from this nutritional modality for up to 6 months. While the number of malnourished children continues to increase from 3.7 million in 2017 to 6.3 million in 2018 [2].

Inadequate exclusive breastfeeding practice also increases the risk of infant death. According to UNICEF, an exclusively breastfed infant has a 14 -fold lower risk of death than a non-breastfed infant [3]. Globally, only $47 \%$ of mothers were exclusively breastfeeding their offspring until 6 months of age in 2018. But in reality, this rate varies from continent to continent: Europe 43.7\%, America 43.9\%, Asia 55.2\%, Africa 41.7\% [4]. Regarding sub-Saharan Africa, although almost all mothers practice breastfeeding, the rate of exclusive breastfeeding is still low, varying between $23 \%$ and $53.5 \%$ [5]. In Côte d'Ivoire, the exclusive breastfeeding rate is still low and contributes directly or indirectly to $33 \%$ of infant and child mortality [6]. The 2016 multiple indicator survey reported an exclusive breastfeeding rate of $23.5 \%$ with, however, disparities across the country's regions. Concerning the region of Gbêkê, the North-East Bouaké health district of which the city of Brobo is part, the breastfeeding rate in 2016 was $22.2 \%$. This breastfeeding rate is below the target of $50 \%$ set by the Ivorian government over the period from 2016 to 2020 [7].

The reasons given to explain this situation are varied, including the socio-economic conditions of the populations, harmful socio-cultural beliefs fostered by ignorance, insufficient monitoring of young infants and the availability of food. The objective of this study, carried out in Brobo, a rural area, is to evaluate the knowledge, attitudes and practices of mothers regarding exclusive breastfeeding in order to reduce infant morbidity and mortality by improving the nutritional status of infants.

\section{Methods}

This was a descriptive and analytical cross-sectional study conducted in Brobo from July to September 2020. The town of Brobo is located in the Gbêkê region, 
in central Côte d'Ivoire, $20 \mathrm{~km}$ from Bouaké, on the Bouaké-M'Bahiakro axis. This town, whose population is predominantly rural, has 5 tribes and 68 villages (Figure 1). According to the 2014 General Census of Population and Housing, Brobo has a population of 41,735 inhabitants, $16 \%$ of whom are between 0 and 5 years old. This locality has 4 first contact health facilities performing curative, preventive and promotional care activities. In 2016 the four health facilities recorded 10,617 consultations of children aged 0 to 14 years, $75 \%$ of whom were under 5 years old.

The study population consisted of mothers and their infants aged $0-24$ months, living in one of the villages of Brobo. The study population consisted of mothers and their infants aged 0 to 24 months, living in one of the villages of Brobo.

Absent, non-consenting mothers and mothers from other tribes present on the day of the study were not included. To select the study sample, we drew lots for the N'denou tribe out of the five tribes in Brobo. Then we selected all the mothers of infants aged 0 to 24 months present at the time of the survey from the twelve villages in this tribe. With the logistical support of the non-governmental organization Enfance Harmonieuse, the selected mothers and their children were grouped together in each village according to the established program. They were interviewed in turn using the standardized infant and young child nutrition survey form of the Food and Agriculture Organization of the United Nations (FAO) [8]. The variables studied were the socio-economic characteristics, attitude and practices of mothers regarding the feeding of the child from 0 to 6 months. The performance threshold for correct responses from respondents was set at $75 \%$. The data were entered and analyzed using Epi info software. Descriptive statistics were used to calculate frequencies and percentages. The PEARSON Chi-square test was used to verify the strength of the relationship between the quantitative variables. The threshold of significance was set for a value of $\mathrm{p}<$ 0.05

\section{Results}

\section{- Epidemiological aspects}

A total of 183 mothers were interviewed. The average age of the mothers was 25 years with extremes of 13 to 49 years. Of the 183 mothers, 49 were under 18 years of age. They were out of school in 51\% (93/183) of cases and single in $61.7 \%(113 / 183)$. The mother had completed at least 4 prenatal consultations in $55 \%$ of the cases and $89 \%$ had given birth vaginally. The mothers interviewed were multiparous in $68 \%$. On average, they had 3 children with extremes ranging from 1 to 10 children. The socio-economic level was modest in $65 \%$ of cases. (Table 1)

The infant was a boy in $50 \%$ of cases with a mean age of 12 months. The age of the infant was between 12 and 24 months in $45 \%$. The nutritional status of the infant was normal in 57.3\%. The normal nutritional status in the age groups of 0 


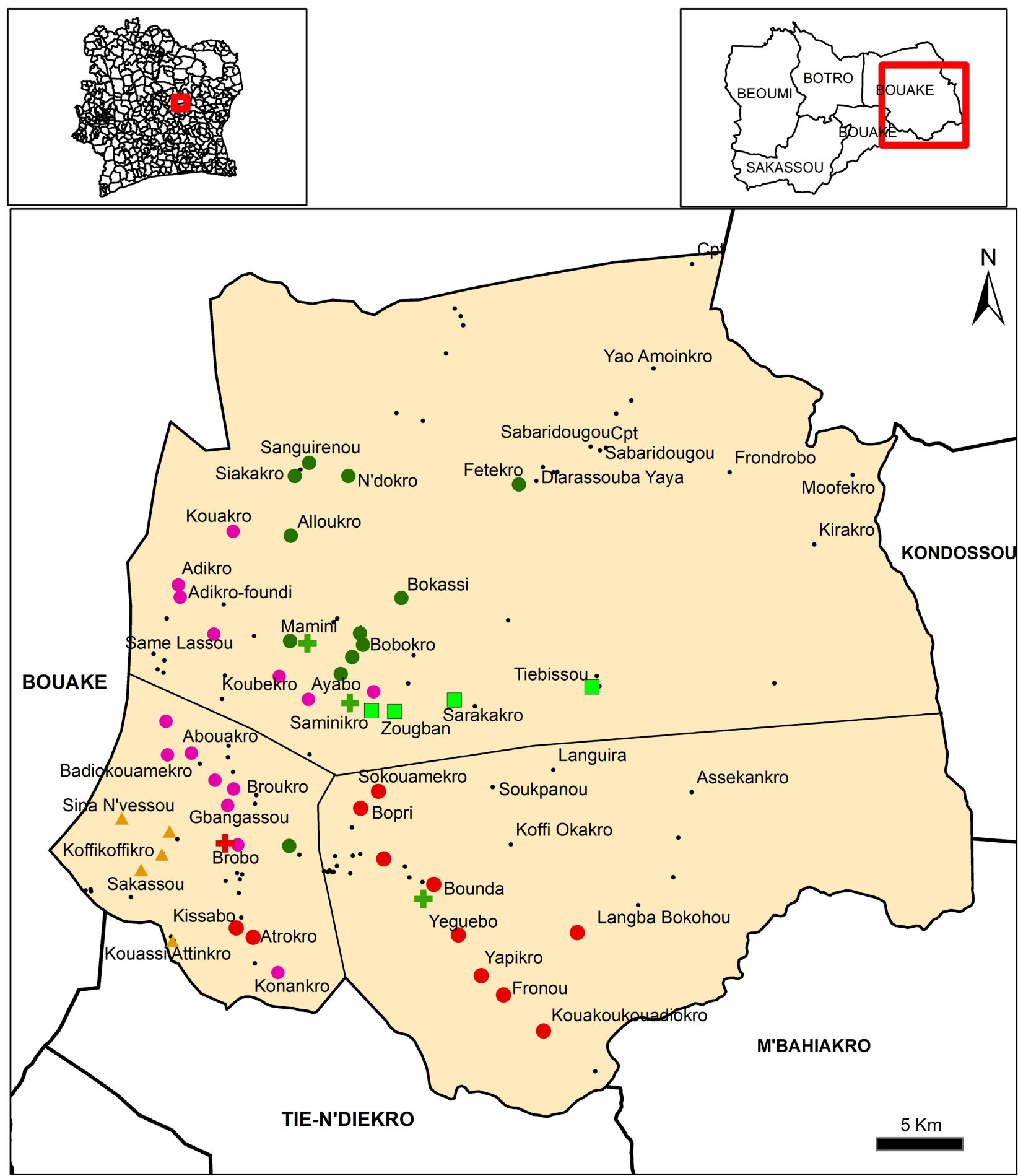

Urban Health Center

Rural Health Center
Droh tribe village

Arrouaye tribe village

$\Delta$ N'Denou tribe village
Lasson tribe village

Akpouessou tribe village

- Other village
Study zone

Neighboring under prefecture

Source; DRS Gbêkê, 2019

Author: SREU Eric, 2021

Figure 1. Administrative boundary of Brobo. 
- 6 months, 7 - 12 months, and 13-24 months was 49\% (29/59), 51\% (22/43), and $65 \%$ (54/83), respectively.

\section{- Mothers' knowledge of exclusive breastfeeding}

The mother was informed about exclusive breastfeeding in $45.9 \%$ of cases. The source of information was the health care provider during Behavior Change Communication (BCC) sessions at the health center in $75 \%$ and during community awareness campaigns in $67 \%$ of cases. Breast milk was recognized as the ideal first food for the newborn in $80 \%$ of cases. They knew the definition of exclusive breastfeeding in $33 \%$ of the cases and the reasons justifying its practice for infants under 6 months of age in $45 \%$ of the cases. The mothers answered in $80 \%$ of the cases that the infant should be breastfed on demand. Knowledge of the different advantages of breast milk for the mother and the child varied from one mother to another (Table 2). However, $26 \%$ of the mothers had a response rate on the benefits of breast milk just above the $75 \%$ threshold.

Table 1. Sociodemographic characteristics of the mother.

\begin{tabular}{clcc}
\hline & Variables & Number & Percentage \\
\hline \multirow{2}{*}{ Age } & Under 18 years old & 49 & 27 \\
& 18 years old to 35 years old & 111 & 61 \\
& Over 35 years old & 23 & 12 \\
Marital status & Single & 113 & 62 \\
& Other & 70 & 38 \\
Level of education & Enrolled in school & 90 & 49 \\
& Not in school & 93 & 51 \\
Activities carried out & Household goods & 95 & 52 \\
& Other & 88 & 48 \\
& Primipare & 59 & 32 \\
& Multiparous & 124 & 68 \\
\hline
\end{tabular}

Table 2. Mothers' knowledge of the benefits of breast milk for the mother and child.

\begin{tabular}{llcc}
\hline & \multicolumn{1}{c}{ Advantage of breast milk } & Number & Percentage \\
\hline \multirow{2}{*}{ Mother } & - Contraceptive measures & $2 / 183$ & 1 \\
& - Economic & $4 / 183$ & 2 \\
& - Strengthening the mother-child bond & $13 / 183$ & 7 \\
& - Protects against cancer Protects against cancer & $29 / 183$ & 16 \\
Child & - Develops intelligence & $2 / 183$ & 1 \\
& - Protects against diarrhea and infections & $33 / 183$ & 18 \\
& - Gives good health & $117 / 183$ & 64 \\
& - Ideal growth & $117 / 183$ & 64 \\
\hline
\end{tabular}


The factor associated with not knowing the definition of exclusive breastfeeding was the mother's lack of schooling ( $\mathrm{OR}=0.26 ; 95 \% \mathrm{CI}[0.14-0.48] ; \mathrm{p}=$ $0.0001)$. The mother not attending school was 3.8 times less likely to know the definition of exclusive breastfeeding than the mother attending school (Table 3)

\section{- Mothers' attitudes and practices}

According to the mothers, breastfeeding from 0 to 6 months was well-founded in $91 \%$ of cases. Mothers of the opposite opinion felt that in $62 \%$ of the cases, the infant was not satisfied when receiving only breast milk. Some mothers ( $7 \%$ of the cases) refused to breastfeed on demand, citing as reasons that this practice would encourage the infant's greed (46\%) and the mother's fatigue (34\%). Early breastfeeding within one hour of delivery was practiced by $2 \%$ of the mothers surveyed, and $63 \%$ said they fed the newborn with colostrum. When colostrum was not given to the newborn, the mothers surveyed offered plain water to drink (74\%; 137/183), infant formula (20\%; 37/183), and juice (13\%; 30/183). The yellowish appearance of colostrum considered as dirty milk $(60,3 \%)$ and the ignorance of mothers (23\%) were the two main reasons mentioned by mothers for not giving colostrum to the newborn. Mixed feeding and predominantly breastfeeding accounted for $49.3 \%$ and $41.30 \%$ respectively. Only $9 \%$ of the mothers in the study population actually practiced exclusive breastfeeding until the age of 6 months. The factors associated with exclusive breastfeeding were primiparity $(\mathrm{OR}=0.30 ; 95 \% \mathrm{CI}[0.09-0.97] ; \mathrm{p}=0.04)$ and not attending school $(\mathrm{OR}=4.94$; 95\% CI [1.09 - 22.2]; $\mathrm{p}=0.03$ ) (Table 3).

The mother's level of education is significantly associated with good knowledge. The educated mother is 3.8 times more likely to know the definition of exclusive breastfeeding than the unschooled mother. The uneducated mother was nearly 5 times more likely to correctly perform exclusive breastfeeding than the educated mother. The multiparous mother was 3.33 times more likely to practice exclusive breastfeeding correctly than the primiparous mother. There were no

Table 3. Factors associated with knowledge and practice of exclusive breastfeeding.

\begin{tabular}{|c|c|c|c|c|c|c|c|c|}
\hline \multirow{2}{*}{ Variables } & \multicolumn{4}{|c|}{ Knowledge } & \multicolumn{4}{|c|}{ Practice of exclusive breastfeeding } \\
\hline & Good & Poor & p-value & Odds ratio/CI & Good & Poor & p-value & Odds ratio/CI \\
\hline Age $<25$ years old & 31 & 72 & & 0.6 & 9 & 85 & & 0.94 \\
\hline Age $>25$ years old & 33 & 47 & 0.117 & {$[0.33-1.13]$} & 9 & 80 & 0.902 & {$[0.35-2.49]$} \\
\hline Not in school & 32 & 61 & & 0.26 & 16 & 102 & & 4. 94 \\
\hline In school & 56 & 28 & 0.0001 & {$[0.14-0.48]$} & 2 & 63 & 0.03 & {$[1.09-22.21]$} \\
\hline Singles & 35 & 77 & & 0.9486 & 12 & 98 & & 1.36 \\
\hline Other & 23 & 48 & 0.8712 & {$[0.50-1.7]$} & 6 & 67 & 0.55 & {$[0.48-3.82]$} \\
\hline Households & 33 & 61 & & 1.17 & 8 & 82 & & 0.71 \\
\hline Other & 28 & 61 & 0.601 & {$[0.63-2.18]$} & 10 & 73 & 0.49 & [0.26 - 1.9] \\
\hline Primiparous & 17 & 42 & & 0.762 & 4 & 79 & & 0.30 \\
\hline Multiparous & 43 & 81 & 0.430 & [0.38 - 1.49] & 14 & 85 & 0.04 & [0.09 - 0.97] \\
\hline
\end{tabular}

CI: Confidence interval. 
other factors associated with the knowledge and practice of exclusive breastfeeding in addition to those in Table 3. The mothers interviewed stated that they had encountered difficulties in $10 \%$ of cases. The difficulties encountered were breast pain $(27 \%)$ and hypogalactorhea $(22 \%)$.

\section{Discussion}

This descriptive cross-sectional study was conducted in a rural setting over a period of 3 months in the N'dènou tribe of the Ahaly Canton of Brobo in Côte d'Ivoire aimed to evaluate the knowledge, attitude and practices of mothers regarding the feeding of infants aged 0 to 6 months. The study revealed that the mothers interviewed had a low level of knowledge about infant feeding from 0 to 6 months and practiced little exclusive breastfeeding in the N'dênou tribe of Brobo. This results in a high proportion of malnourished children. These results must be qualified. The method used relies on the memory of the mothers, which exposes them to memory bias. Nevertheless, it is the standardized tool that the FAO [8] recommends for the evaluation of exclusive breastfeeding. In addition, since mothers were grouped together and interviewed in turn, it is possible that the first mothers interviewed gave their answers to other mothers who had not yet been interviewed. To control for this bias, at the end of the interview the mother was asked not to share her answers with the other mothers. Despite the methodological limitations, the study addresses, for the first time, the problem of exclusive breastfeeding in rural Brobo. It is therefore an important source of information that could serve as a starting point for other more in-depth studies. The results of this study give rise to the following points of discussion with respect to the socio-demographic characteristics, knowledge, attitudes and practices of mothers regarding the feeding of infants from 0 to 6 months.

\section{- At the epidemiological level}

The average age of the mothers was 25 years with extremes ranging from 13 to 49 years. This young age is only a reflection of the population in Côte d'Ivoire. According to the general population census in 2016, 1/3 of women are under 35 years of age [7]. Our results are superimposed on those of Savadogo et al. [9] in Burkina Faso and Kouassi [10] in Abidjan. One mother out of two has never attended school. This rate could be explained by the low schooling rate of women in Côte d'Ivoire, particularly in rural areas. Indeed, according to the results of the 2016 general population and housing census, the schooling rate for girls was $47 \%$. In addition, Cote d'Ivoire was among the 10 countries in the world least placed in terms of girls' education with a rate of 52\% according to Unesco [7]. Kumar et al. [11] in India and Savadogo et al. [9] in Burkina Faso reported $22.8 \%$ and $90.8 \%$ respectively. The mothers in the study engage in unpaid informal activities on a monthly basis. In almost half of the cases (52\%), they are housewives with a low socioeconomic level in $65 \%$ of the cases. The study by Junaid et al. [12] in India and Awaliyah et al. [13] in Indonesia found that 28.5\% and $75 \%$ of the mothers were low socioeconomic. First-time mothers accounted 
for 32\%; Awaliyah et al. [13] in Indonesia and Savadogo et al. [9] in Burkina Faso reported $34.8 \%$ and $25.9 \%$. The youthfulness of the mothers as well as the generally high fertility rate, 154.7 per thousand women aged 15 - 49 years in Côte d'Ivoire [7], certainly explains the result in terms of pregnancy and parity recorded in the study. The study reveals that in infants under 6 months of age, $91 \%$ of mothers introduced food other than breast milk into the child's diet. And also that the infant has in $51 \%$ of cases undernutrition. According to WHO [14], giving water or other food during this period reduces the supply of nutrients from breast milk to the infant and promotes malnutrition. In the age group of 6 to 11 months, and 12 to 24 months the study reveals a respective rate of malnourished children of $49 \%$ and $35 \%$. This implies that the foods used in addition to the breast for weaning do not cover all the nutritional needs of the infant. This is probably due to a variety of reasons, including food availability, food accessibility, food prohibitions, food choice in relation to socio-cultural considerations, etc.

\section{- Mothers' knowledge of exclusive breastfeeding}

The study reveals that mothers had information on exclusive breastfeeding in $45.9 \%$ of cases with health care providers as the main source of information. Diawara et al. [15], in Mali in 2015 reported a rate of $23.5 \%$ in rural areas and the different sources of information were the media and IEC sessions at the health center. The study by Niguse et al. [16], conducted in a town in southeastern Ethiopia, reported $93.5 \%$ of mothers who had received information. Regarding knowledge of the definition of MEA, 33\% of mothers had a good definition of MEA. Our result is lower than that of Rabevazaha et al. [17]. The difference observed could be methodological. Indeed, Rabevazaha's study was a multicenter hospital study conducted over a 1-month period. The same advantages of breast milk have been described in the literature but in different proportions [11] [18]. The educated mother was 3.8 times more likely to know the definition of exclusive breastfeeding than the uneducated mother in the study. This confirms the need for an alternative communication approach for unschooled mothers. This approach could be the use of local languages for outreach to mothers through community health workers or community opinion leaders..

\section{- Mothers' attitudes and practices regarding exclusive breastfeeding}

In the study, $91 \%$ of the mothers had a good perception of the concept of exclusive breastfeeding. This may be due to the fact that breastfeeding is a practice that values women in most traditional rural societies in Africa, Asia, and South America. Despite the good predisposition of mothers to practice exclusive breastfeeding in the study, only $9 \%$ of them did so up to 6 months. This reported exclusive breastfeeding rate is below the national average of $23 \%$. According to Dillon et al. [19], while the concept of exclusive breastfeeding is logically accepted, there are many socio-cultural barriers to its implementation in developing countries. Among the socio-cultural barriers is the ignorance of mothers that generates bad beliefs about breast milk. In the study, $62 \%$ of mothers wrongly 
believe that infants are not satiated when they receive breast milk alone and should receive other substances in addition. Also, some mothers (7\%) refuse to breastfeed on demand because this practice would encourage the infant to be greedy. These misconceptions about breast milk and its nutritional value probably explain why $41.3 \%$ of rural mothers in Brobo give their infants water to drink in addition to breast milk. This practice is common in Sub-Saharan Africa and has been reported by other authors in the literature [18] [20]. Supplementing infants with other substances before 6 months of age reduces the amount of breastmilk available to the infant and exposes the infant to malnutrition. The discrepancy between the behavior and the practice of these often young mothers in Brobo also leads us to point to the harmful socio-cultural influence of older people providing mothering to young mothers in rural areas. However, this harmful influence of the environment on the mother seems to diminish as the maternity years go by in rural Brobo. Multiparous mothers acquire their own experience in breastfeeding and are less influenced by community practices in rural areas, such as giving water or decoctions to make the newborn stronger, or to treat hiccups. This certainly explains why multiparous mothers were 3.33 times more likely to correctly perform exclusive breastfeeding than primiparous mothers in the study. The study also found that the uneducated mother was almost 5 times more likely to correctly perform exclusive breastfeeding than the educated mother. The out-of-school mother in rural Brobo does not have a job that requires her to be near her child. The close daily contact between the child and the mother is a factor that favors breastfeeding and is recommended by the Baby-Friendly Hospital Initiative for the promotion of exclusive breastfeeding. In the study, breastfeeding within one hour was $2 \%$, well below the $36 \%$ reported nationally by the national program for maternal and child health in Côte d'Ivoire [21]. Kumar et al. [11] in India and Kamga [22] in Niger reported $37.2 \%$ and $90.5 \%$ respectively. This low rate reported in the study may be explained in part by the high rate of home delivery in this region, 35\%, reported by Akaffou et al. [21] in 2019. Other reasons have been cited by authors [22] [23] to explain the decline of exlusive breastfeeding in sub-Saharan Africa, including loss of traditional values, migration of families to cities, delay in first feeding, and undue commercial pressure (advertising) from artificial milk manufacturers. The study found that $64.3 \%$ of mothers surveyed gave colostrum to their newborns, compared to one-third of mothers who did not. In Hitachi et al. [24] study in Niger, the proportion of mothers who had given colostrum to the newborn was higher, $97.9 \%$ of cases. Mothers refusing to give colostrum to the newborn in the study cited as the main reason (60.3\%) that the colostrum is dirty because of the yellowish color and unfit for consumption. This belief of "bad colostrum", wrongly considered as dirty, was also reported by Kamga [22]. However, the ingestion of colostrum represents, in addition to its high nutritional value, a factor of adaptation of the newborn to life outside the womb by reducing the risk of gastrointestinal diseases, by reinforcing immunity and by influencing the intestinal micro- 
biota [25]. In the study, mothers encountered difficulties in $10 \%$ of cases during breastfeeding practice. These were mainly hypogalactorhea $(27 \%)$ and breast pain (22\%). In the study by Eboua et al. [26], in Abidjan in 2018, the proportion of breastfeeding mothers presenting a difficulty during breastfeeding was $53 \%$. The difficulties reported were hypogalactorrhea $36.4 \%$, the child's thirst $28.8 \%$, the mother's professional activity $15.4 \%$ and the mother's hospitalization $9.6 \%$. Diawara [15] in Mali reported 35.5\% difficulties. In the study by Diawara [15], the difficulties reported were mainly hypogalactorhea $(63 \%)$ and breast pain (25\%). The lack of mastery of breastfeeding technique by rural mothers in Brobo could explain the occurrence of hypogalactorhea and breast pain encountered during breastfeeding.

\section{Conclusion}

This study shows that the knowledge and practice of mothers interviewed in rural Brobo regarding exclusive breastfeeding are insufficient, although the majority of mothers have a good perception of this method of feeding young infants. The factor that negatively influences mothers' knowledge of exclusive breastfeeding is their low level of education. As far as practice is concerned, it is the high level of schooling and primiparity. To improve the rate of exclusive breastfeeding in rural areas of Brobo, we recommend raising mothers' awareness of the benefits of exclusive breastfeeding in the local language, setting up breastfeeding support groups in the villages and revitalizing the Baby-Friendly Hospital Policy.

\section{Acknowledgements}

Prof. PLO Kouié Jeannot, Mr. KOUADIO Kouamé René and Mrs. KOUADIO Eveline Epouse DANO of the NGO Enfance Harmonieuse for their logistical support during the data collection phase of the study.

\section{Contribution of the Authors}

All the authors contributed intellectually to the realization of the study.

\section{Conflicts of Interest}

The authors declare no conflicts of interest regarding the publication of this paper.

\section{References}

[1] UNICEF (2018) 2018 Global Nutrition Report Reveals Malnutrition Is Unacceptably High and Affects Every Country in the World, but There Is Also an Unprecedented Opportunity to End It.

https://www.unicef.org/press-releases/2018-global-nutrition-report-reveals-malnutr ition-unacceptably-high-and-affects

[2] United Nations Children's Fund Regional Office for West and Central Africa Dakar. 
https://www.unicef.org/wca/fr

[3] Domino, M. (2012) Exclusive Breastfeeding: An Absolute Necessity.

https://www.unicef.fr/article/l-allaitement-maternel-exclusif-une-necessite-absolue

[4] Zong, X.N., Wu, H., Zhao, M., Magnussen, C.G. and Xi, B. (2021) Global Prevalence of WHO Infant Feeding Practices in 57 LMICs in 2010-2018 and Time Trends since 2000 for 44 LMICs. E Clinical Medicine, 37, Article ID: 100971. https://www.thelancet.com/pdfs/journals/eclinm/PIIS2589-5370(21)00251-0.pdf https://doi.org/10.1016/j.eclinm.2021.100971

[5] SUN (2018) Annual Progress Report Force Nutrition in West and Central Africa Movement SUN Annual Progress Report 2018.

https://scalingupnutrition.org/wp-content/uploads/2019/01/SUN_Report_FR_2018. pdf

[6] Republic of Côte d'Ivoire (2015) Analysis of the Nutritional Situation in Côte d'Ivoire Report.

https://mics-surveys-prod.s3.amazonaws.com/MICS5/West\%20and\%20Central\%20Afri ca/C\%C3\%B4te\%20d\%27Ivoire/2016/Final/Cote\%20d\%27Ivoire\%202016\%20MICS_Fre nch.pdf

[7] Republic of Côte d'Ivoire, National Institute of Statistics (INS) (2016) Multiple Indicator Cluster Survey 2016, Key Results Report. Abidjan. http://www.pnmin.gouv.ci/fichier/doc/PNMN_2016_2020_15_08_16.pdf

[8] Macías, F.Y. and Glasauer. P. (2016) Guide to Assessing Nutrition-Related Knowledge, Attitudes and Practices. Food and Agriculture Organization of the United Nations.

[9] Savadogo, B., Léon, G., Ilboudo, B. and Kinda, M. (2018) Exclusive Breastfeeding Practice and Its Factors in Rural Areas of Burkina Faso. Open Journal of Epidemiology, 8, 67-75. https://doi.org/10.4236/ojepi.2018.82006

[10] Kouakou, K.F. (2014) An Anthropological Approach to Exclusive Breastfeeding in Côte d'Ivoire: Knowledge, Attitudes and Practices of Mothers. African Journal of Anthropology, 16, 43-56.

[11] Kumar, S., Jha, S.K., Singh, A., Rawat, C.M.S., Awasthi, S., Bano, M., et al. (2015) Knowledge, Attitude and Practices (KAP) Regarding Breastfeeding: A Community based Cross Sectional Study from Rural Uttrakhand. Healthline Journal, 6, 17-22.

[12] Junaid, M. and Patil, S. (2018) Breastfeeding Practices among Lactating Mothers of a Rural Area of Central India: A Cross-Sectional Study. International Journal of Community Medicine and Public Health, 5, 5242-5245. https://doi.org/10.18203/2394-6040.ijcmph20184797

[13] Awaliyah, S.N., Rachmawati, I.N. and Rahmah, H. (2019) Breastfeeding Self-Efficacy as a Dominant Factor Affecting Maternal Breastfeeding Satisfaction. BMC Nursing, 18, Article No. 30. https://doi.org/10.1186/s12912-019-0359-6

[14] WHO/UNICEF (2003) Global Strategy for Infant and Young Child Feeding. https://www.who.int/nutrition/publications/gs_infant_feeding_text_fre.pdf

[15] Diawara, Y.D. (2015) Study of Factors Associated with Exclusive Breastfeeding among Mothers of Children Aged 0 to 6 Months in Beleko in the Health District of Fana. University of Bamako, Bamako. http://www.keneya.net/fmpos/theses/2015/med/pdf/15M165.pdf

[16] Niguse, T., Frehiwot, H., Dinu, A. and Eyerus, D. (2016) Knowledge, Attitude and Practice towards Exclusive Breastfeeding among Lactating Mothers in Mizan Aman Town, Southwestern Ethiopia: Descriptive Cross-Sectional Study. International Breastfeeding Journal, 11, Article No. 3. https://doi.org/10.1186/s13006-016-0062-0 
[17] Rabevazaha, N.A., Ranivoson, A.H., Rakotoarisoa, L.A. and Robinson, A.L. (2019) Mothers' Knowledge, Attitudes and Practices on Exclusive Breastfeeding in Antananarivo. Revue Malgache de Pédiatrie, 2, 102-109.

[18] Mariko, O. (2009) Study on the Knowledge, Attitudes and Practices of Women on Exclusive Breastfeeding in the District of Sogoniko in Commune VI of the District of Bamako. Thèse de Médecine présentée et soutenue par MARIKO Oumar (FMPOs), University of Bamako, Bamako. http://www.keneya.net/fmpos/theses/2010/med/pdf/10M380.pdf

[19] Dillon, J.C. and Imbert, P. (2003) Breastfeeding in Developing Countries: Evolution and Current Recommendations. Med Trop, 63, 400-406.

[20] Mensah, J. (2019) Late Neonatal Morbidity and Mortality in Rural Areas: Results of a Prospective Survey about 254 Newborns Born at Home in Brobo (Ivory Coast), 2019. Thesis Med. No 818/2019, Université Alassane Ouattara, Bouaké.

[21] Akaffou, A.E., Yeboua, Y.K.R., Avi, C., Aka-Tanoh, K.A., Yao, K.C., Azagoh-Kouadio, R., N'guessan-Sika, R., Akanji, I.A., Adou, L.R., Sanogo, C.S., Coulibaly, D., Plo, K.J. and Asse, K.V. (2019) Epidemiological Profile of 260 Rural Home Births in Ahaly canton of Brobo (Côte d'Ivoire). Archives of Pediatrics and Neonatology, 2, 59-69.

[22] Kamga, B.G. (n.d.) Study of Mothers' Knowledge and Practices on Breastfeeding at the Provincial Hospital and at the PMI in Bafoussam, Cameroon Thèsis Mèd. Bangangté Higher Institute of Science and Health.

https://www.memoireonline.com/05/12/5858/m_Etude-des-connaissances-et-pratiq ues-des-meres-sur-l-allaitement-maternel--lhpital-provinci19.html

[23] Jhugroo, Y. (1992) Breastfeeding: An Ongoing Debate. IBFAN Courier.

[24] Hitachi, M., Honda, S., Kaneko, S. and Kamiya Y. (2019) Correlates of Exclusive Breastfeeding Practices in Rural and Urban Niger: A Community-Based Cross-Sectional Study. International Breastfeeding Journal, 14, Article No. 32. https://doi.org/10.1186/s13006-019-0226-9

[25] Sohn, K., Kalanetra, K.M., Mills, D.A. and Underwood, M.A. (2016) Buccal Administration of Human Colostrum: Impact on the Oral Microbiota of Premature Infants. Journal of Perinatology, 36, 106-111. https://doi.org/10.1038/jp.2015.157

[26] Eboua, T.K.F., N’guessan, R., Aké-Assi, M.H., et al. (2018) Exclusive Breastfeeding: Prevalence and Impact on Morbidity of Children Hospitalized in the Pediatric Ward of the CHU of Yopougon, Côte d'Ivoire. Journal de la Recherche Scientifique de P Université de Lomé, 20, 519-527.

https://www.ajol.info/index.php/jrsul/article/view/184058 